\title{
Numerical analysis of interlaminar stresses in open-hole laminates under compression
}

A. Solis. ${ }^{a}$, S. Sanchez-Saez ${ }^{\mathrm{a}}$, X. Martinez ${ }^{\mathrm{b}, \mathrm{c}}$, E. Barbero-Pozuelo ${ }^{\mathrm{a} *}$

a. Department of Continuum Mechanics and Structural Analysis. University Carlos III of Madrid.

b. International Centre for Numerical Methods in Engineering (CIMNE).

c. Department of Nautical Science and Engineering. Polytechnic University of Catalonia (UPC).

*Corresponding author

Telephone number: +34916249965

Email address: ebarbero@ing.uc3m.es

\begin{abstract}
In this paper, the interlaminar stresses in open-hole laminates subjected to compressive loads are analysed using a numerical model. This model implements the Serial/Parallel Mixing Theory (S/PMT) and a Continuum Damage Mechanics (CDM) approach. The S/PMT estimates the global stiffness in the laminate from fibre and matrix properties. The CDM approach models the damage initiation due to fibre microbuckling. The global response estimated by the model was verified with experimental data from the literature. The model predicts that the damage initiates in the laminate middle-plane where the thickest block of plies oriented in the load direction is located, and progressively propagates to the nearest block of layers with the same orientation. Two laminate stacking sequences were analysed. The interlaminar stresses around the hole presented symmetry with respect to the load direction and the perpendicular axis, being
\end{abstract}


located the maximum and minimum values in different angular positions for each stress component and laminate.

Keywords: open-hole; compression; interlaminar stresses; fibre microbuckling

\section{Introduction}

Structural components usually have notches and holes that produce a phenomenon of in-plane stress concentration that could reduce their strength significantly. In addition, interlaminar stresses appear in these components close to the free-edges, even when inplane loads are applied. These stresses can be relevant and contribute to the laminate failure due to the low interlaminar strength of composite laminates [1]. Interlaminar stresses control two damage modes, shear failure and delamination. The shear interlaminar stresses can produce matrix crack at the free-edge, and the normal stress in the thickness direction contribute to generate damage by delamination [2, 3]. The analysis of the interlaminar stresses at the free-edge in laminates has been studied since the 70s of the last century [4]. Since then many works have focused on this topic, mainly on the free-edge of a laminate because the modelization of a straight edge is simpler [5-8]. The stress field around the hole is clearly three-dimensional and with large gradients in all the components [9, 10]. Some works use analytical models [11, 12] or numerical models $[1,8]$ to estimate the three-dimensional stress field in intact laminates. When damage appears, the stresses change and purely elastic models can not be considered valid.

The analysis of open-hole laminates under compressive loads is important since the compressive strength in the direction of the fibres is significantly lower than the tensile 
strength, in the order of $60 \%$ for many composites, and thus the damage initiate at lower stress [10]. In addition, the failure mechanisms under compressive and tensile loads are different. There are several mechanisms that can contribute the laminate failure [13]. For example, under tensile loads, the fibre failure is controlled by fibre breakage, while in compression, the mechanism that produce the fibre failure is the microbuckling [10, 14, 15]. The damage of laminate begins by fibre microbuckling in sublaminate scaled laminates with plies at $0^{\circ}[16,17]$ and can propagate by other failures modes such as matrix cracking and delamination $[18,19]$. The damage of laminates with ply at $0^{\circ}$ (sublaminate level scaling) begins by fibre microbuckling $[16,17]$ and can propagate by other failures modes such as matrix cracking and delamination [18, 19]. Many works can be found in the scientific literature on modelling of in-plane stresses and damage evolution around a hole in a laminate subjected to tensile [20-23] and compressive loads $[9,10,16,24]$. In spite of these works, there is a necessity to continuous working in the knowledge of the problem of open-hole laminates subjected to compressive loads.

Several methodologies can be applied to study laminates containing holes subjected to different load states. The simplest models only can predict the final failure [25-27]. More complex models can predict damage initiation and growth [23, 28-35] In a previous work, the authors analysed the edge effect in laminates without damage subjected to tensile loads [8] due the symmetries of the stress field of this problem some simplification reduced the complexity of the model. To analyse laminates with holes and with damage more complex models are needed.

The serial-parallel mixing theory (S/PMT) [36] is an alternative to other methodologies such as mesomechanical or micromechanical models. Some of these models require the 
estimation of a large number of parameters that are difficult to measure experimentally. Mesomechanical models consider the material as a homogeneous continuous medium and have limitations for predicting fibre and matrix failure separately. Micromechanical models are based on a detailed definition of the heterogeneity of the composite material and are extremely complex and difficult to apply to structural problems [36]. As described by his authors, S/PMT combines speed and accuracy and is based on combining relatively simple constitutive equations for the constituents, fibre and matrix, and at the same time is able to reproduce the anisotropy and heterogeneity of a laminate. This theory has been applied successfully to predict the fatigue behaviour [37] and the evolution of delamination [38] in laminates. S/PMT has not been used to analyse the interlaminar stresses and damage initiation in problems with stress concentration. In this work, a phenomenological model was used by combining S/PMT with a CDM to predict the interlaminar stresses near the free-edges and the hole-edge at the damage onset. The method proposed analysed the microbuckling effect of the fibres oriented according to the load direction, developed in two laminates with different stacking sequences. This failure mode initiation was predicted thanks to the possibility of defining different threshold limits for tensile and compressive loads. This avoids the need for the micromechanical formulation developed in [39] regarding fibre microbuckling or any other solution that includes the explicit complexity of the physics involved. The mentioned complexity is one of the main difficulties in compression problems as revealed in [16]. The model was calibrated using experimental data from unidirectional unnotched laminates and it was validated using the experimental results of multidirectional unnotched and notched laminates subjected to a compression load [40]. 


\section{Model description and validation}

In this work, a Continuum Damage Mechanics (CDM) model was used to simulate the damage initiation process due to fibre microbuckling in laminates subjected to compressive loads. The Serial/Parallel Mixing theory (S/PMT) [36] was applied to characterize the mechanical behaviour of a multidirectional laminate by combining the fibre and matrix mechanical properties. The CDM model and S/PMT were implemented in an iterative finite element algorithm developed for non-linear problems in this work. A general scheme of the algorithm is summarized in Fig.1.

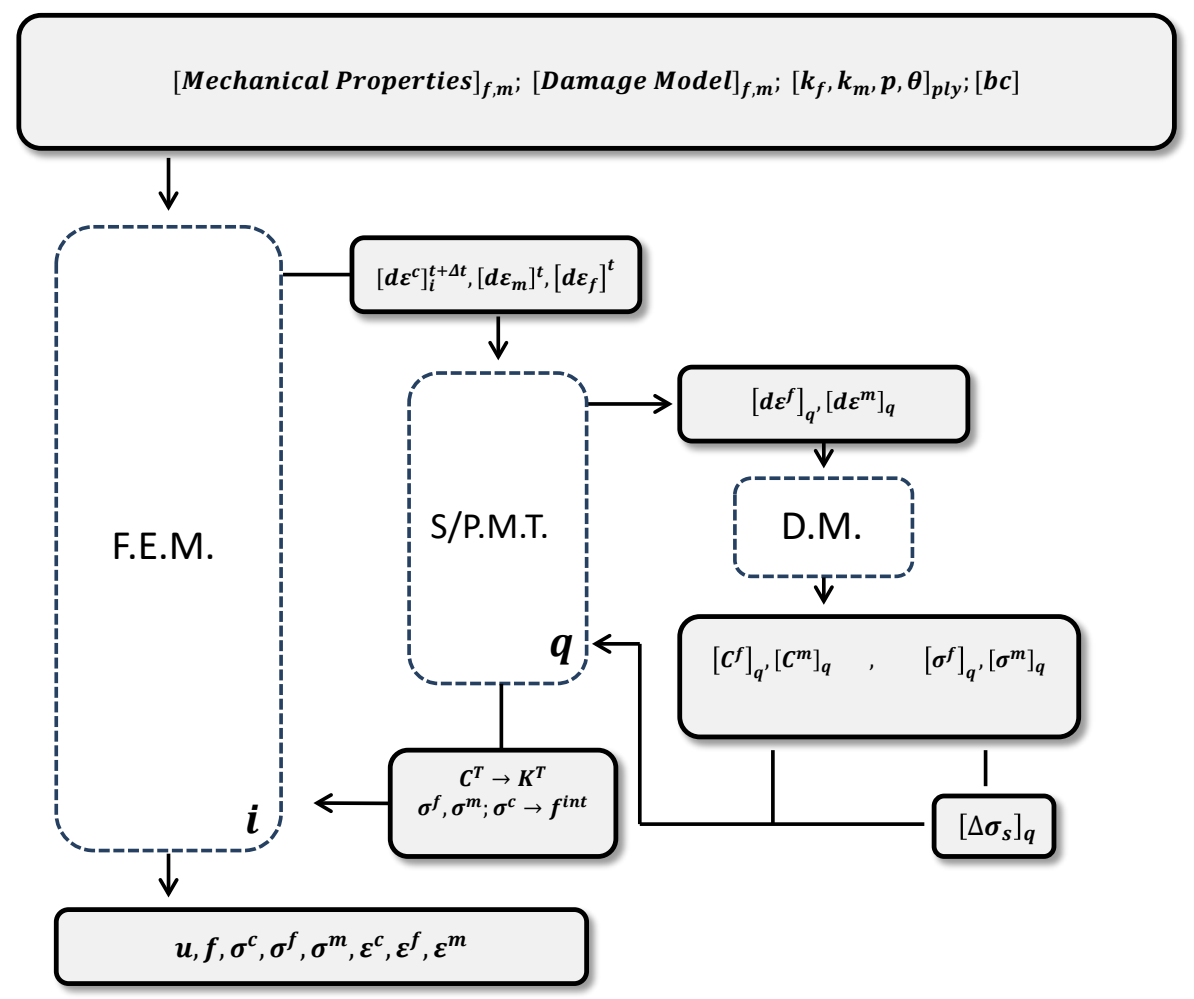

Figure 1. General scheme of the method

The algorithm is composed of two loops. An outer loop (with iteration index $i$ ) defines the equilibrium between internal and external forces in the Finite Element Method 
(FEM), and an inner loop (with iteration index $q$ ) that balances the iso-stress components according to the relations imposed by S/PMT.

The outer loop inputs are the fibre and matrix mechanical properties and damage parameters, all ply definition constants (volumetric fractions, directions with parallel behaviour and fibre direction) and boundary conditions. Once convergence is reached, the outer loop produces as outputs, the nodal forces $f$ and displacements $u$, and the strain and stress components of composite, fibre and matrix $\left(\varepsilon_{c}, \varepsilon_{f}, \varepsilon_{m}, \sigma_{c}, \sigma_{f}, \sigma_{m}\right)$. For each Gauss point and element in the model, the inner loop uses a Newton-Raphson iterative scheme to obtain the strain and stress tensors of the composite that verify the iso-strain and iso-stress conditions required by the S/PMT. These block inputs are composite strains in the next time step $\left[d \varepsilon^{c}\right]_{i}^{t+\Delta t}$ and fibre $\left[d \varepsilon_{f}\right]^{t}$ and matrix strains $\left[d \varepsilon_{m}\right]^{t}$ in the step $t$. Moreover, the outputs of this block are the composite $\sigma_{c}$, fibre $\sigma_{f}$ and matrix stresses $\sigma_{m}$ needed for the internal forces calculation in the outer loop. S/PMT also produces the composite constitutive tensor $C^{T}$ needed for the global stiffness matrix $K^{T}$ calculation in the following outer loop iteration.

From the fibre $\left[d \varepsilon_{f}\right]_{q}$ and matrix $\left[d \varepsilon_{m}\right]_{q}$ strains, the explicit damage model calculates the fibre $\left[C^{f}\right]_{q}$ and matrix $\left[C^{m}\right]_{q}$ constitutive tensors and the stresses in each $q$ iteration of the inner loop. S/PMT provides the composite constitutive tensor by combining fibre, and matrix constitutive tensors and reduces, through successive iterations, the difference between fibre and matrix serial stresses.

\subsection{Serial/Parallel Mixing Theory}

This theory is based on the following hypothesis: 
- The composite material is made of two different components, fibre and matrix. The material is modelled as homogeneous with a perfect bond between the components, where the component participations are proportional to their volumetric fractions.

- The components exhibit a parallel behaviour in the fibre direction (iso-strain) and a serial behaviour (iso-stress) in the perpendicular direction.

In this work, a separation between parallel and serial components was implemented by rearranging the components of the strain and stress vectors written according to Voigt notation. The reordering can be expressed by using a projection matrix $P$. The $\varepsilon$ and $\sigma$ vectors are transformed into $\varepsilon^{\prime}$ and $\sigma^{\prime}$ where the parallel components are placed in the first rows and then, the remaining serial components. In such a way:

$$
\varepsilon^{\prime}=P \varepsilon=\left(\begin{array}{c}
\varepsilon_{p} \\
\varepsilon_{s}
\end{array}\right) ; \quad \sigma^{\prime}=P \sigma=\left(\begin{array}{c}
\sigma_{p} \\
\sigma_{s}
\end{array}\right)
$$

Each ' $i j$ ' element in the $P_{i j}(6 \mathrm{x} 6)$ matrix is 1 if the ' $j$ ' ${ }^{\text {' }}$ ' component in $\varepsilon$ or $\sigma$ corresponds to the ' $i{ }^{t h}$ ' component of $\varepsilon^{\prime}$ or $\sigma^{\prime}$ and is 0 in any other case. $P$ can be split into two matrices $P_{p}$ and $P_{s}$. The first $n$ rows in $P_{p}$ correspond to the first $n$ rows in $P$ while the remaining rows contain null elements, with $n$ the number of components with parallel behaviour. Complementarily, the last (6-n) rows in $P_{S}$ correspond to the last (6$n$ ) rows in $P$ while the other $n$ rows contain null elements. This can be expressed as:

$$
P=P_{p}+P_{s}
$$

In the model proposed, only the fibre direction (in each ply local axis) acts according to a parallel behaviour so that $n=1$ and the parallel components are $\varepsilon_{x x}$ and $\sigma_{x x}$. The theory enables any constitutive law for the fibre and matrix to be considered separately. In this work, given that fibre microbuckling determines laminate failure, the fibre was modelled according to a continuum isotropic damage model whereas the matrix was 
modelled as an elastic material. Under these conditions, fibre and matrix constitutive laws are:

$$
\sigma_{f}=\left(1-d_{f}\right) C_{f} \varepsilon_{f} ; \quad \sigma_{m}=C_{m} \varepsilon_{m}
$$

where $C_{f}$ and $C_{m}$ are the constitutive tensors of fibre and matrix and $d_{f}$ is the scalar damage fibre variable. The serial/parallel decomposition described above can be applied in (3) by using the $P$ matrix defined in (1) and (2):

$$
\sigma_{i}^{\prime}=\left(\begin{array}{l}
\sigma_{p} \\
\sigma_{s}
\end{array}\right)_{i}=\left(1-d_{i}\right) C_{i}^{\prime} \varepsilon_{i}^{\prime}=\left(1-d_{i}\right)\left(\begin{array}{ll}
C_{p p} & C_{p s} \\
C_{s p} & C_{s S}
\end{array}\right)_{i}\left(\begin{array}{l}
\varepsilon_{p} \\
\varepsilon_{s}
\end{array}\right)_{i} ; \quad i=f, m
$$

where:

$$
\begin{aligned}
C_{i}^{\prime}=\left(P_{p} C_{i} P_{p}^{T}\right. & \left.+P_{p} C_{i} P_{s}^{T}+P_{s} C_{i} P_{p}^{T}+P_{s} C_{i} P_{s}^{T}\right) \\
& =\left(\begin{array}{cc}
C_{p p}(n \times n) & C_{p s}(n \times(6-n)) \\
C_{s p}((6-n) \times n) & C_{s s}((6-n) \times(6-n))
\end{array}\right)_{i} ; i=f, m
\end{aligned}
$$

In (5), the submatrix dimensions are included in brackets. Given that the matrix behaves elastically, $d_{m}=0$, while $d_{f}$ is given by the continuum damage model described later. The relations between composite strains and stresses and fibre and matrix strains and stresses are given by the usual rule of mixtures applied according to a parallel and serial decomposition as described in (1):

$$
\begin{array}{cc}
\left(\sigma_{p}\right)_{c}=k^{f}\left(\sigma_{p}\right)_{f}+k^{m}\left(\sigma_{p}\right)_{m} & (\text { parallel behaviour) } \\
\left(\varepsilon_{s}\right)_{c}=k^{f}\left(\varepsilon_{s}\right)_{f}+k^{m}\left(\varepsilon_{s}\right)_{m} & \text { (serial behaviour) }
\end{array} ;
$$

where $c$, $f$ and $m$ respectively represent composite, fibre and matrix and $k^{f}$ and $k^{m}$ are the volumetric fractions. The closure equations imposed by the theory can be expressed easily using the serial/parallel separation described in (1):

$$
\begin{array}{cc}
\left(\varepsilon_{p}\right)_{f}=\left(\varepsilon_{p}\right)_{m}=\left(\varepsilon_{p}\right)_{c} & \text { (parallel behaviour) } \\
\left(\sigma_{s}\right)_{f}=\left(\sigma_{s}\right)_{m}=\left(\sigma_{s}\right)_{c} & \text { (serial behaviour) }
\end{array} ;
$$


The S/PMT algorithm calculates the composite, fibre and matrix stresses in the instant $t+\Delta t$ from the composite strains at the instant $t+\Delta t$ (obtained in the iteration $i$ of the outer loop) and fibre and matrix strains at the instant $t$. The first step is the separation of strains and stresses in the serial and parallel components as described in (1). According to the first equation in (7), composite, fibre and matrix parallel strains are equal, however, serial strains are unknown and their calculation needs an initial approximation for either the matrix or the fibre. Rastellini [41] proposed as an initial approximation for the increment of matrix serial strain:

$$
\begin{aligned}
{\left[\left(\Delta \varepsilon_{s}\right)_{m}\right]_{o}=} & \left(k^{m}\left(C_{s s}\right)_{f}+k^{f}\left(C_{s s}\right)_{m}\right)^{-1}\left[\left(C_{s s}\right)_{f}\left(\Delta \varepsilon_{s}\right)_{c}\right. \\
& \left.+k^{f}\left(\left(C_{s p}\right)_{f}-\left(C_{s p}\right)_{m}\right)\left(\Delta \varepsilon_{p}\right)_{c}\right]
\end{aligned}
$$

where $\left[\left(\Delta \varepsilon_{s}\right)_{m}\right]_{o}=\left[\varepsilon_{s}^{m}\right]_{o}^{t+\Delta t}-\left[\varepsilon_{s}^{m}\right]^{t}$. Constitutive tensors showed in (8) are the fibre and matrix tangent constitutive tensors in the instant $t$, decomposed as described in (5). Once $\left[\varepsilon_{s}{ }^{m}\right]_{q}^{t+\Delta t}$ is determined, $\left[\varepsilon_{s}{ }^{f}\right]_{q}^{t+\Delta t}$ (in the iteration $q$ of the inner loop) can be cleared from the second equation of (6):

$$
\left[\varepsilon_{s}^{f}\right]_{q}^{t+\Delta t}=\frac{1}{k^{f}}\left[\varepsilon_{s}^{c}\right]^{t+\Delta t}-\frac{k^{m}}{k^{f}}\left[\varepsilon_{s}^{m}\right]_{q}^{t+\Delta t}
$$

When parallel and serial components of fibre and matrix strains are determined, these have to be rearranged (according to the original order of $\varepsilon$ and $\sigma$ ) to apply the constitutive law of each component given in (3). After this, the fibre and matrix stresses are calculated and the serial components should verify:

$$
\left[\Delta \sigma_{s}\right]_{q}=\left[\sigma_{s}{ }^{m}\right]_{q}^{t+\Delta t}-\left[\sigma_{s}^{f}\right]_{q}^{t+\Delta t} \leq \text { tolerance }
$$

If $\left[\Delta \sigma_{s}\right]_{q}$ is less than the tolerance defined in (10), the strain-stress state is correct and the stress state of the composite can be calculated through the application of the inverse second equation of (1). Otherwise, the stress state has to be corrected with the Newton- 
Raphson method proposed by Rastellini et al. [36], where the initial approach is minimized using the Jacobian of the residual stresses. This Jacobian (in the iteration $q$ of the inner loop) can be written as follows:

$$
J_{q}=\left[\frac{\partial\left(\Delta \sigma_{s}\right)}{\partial \varepsilon_{s}{ }^{m}}\right]_{\left[\varepsilon_{s}{ }^{m}\right]_{q}^{t+\Delta t}}=\left[\left(C_{s s}\right)_{m}\right]_{q}+\frac{k^{m}}{k^{f}}\left[\left(C_{s s}\right)_{f}\right]_{q}
$$

This Jacobian is inserted in a Newton-Raphson scheme that provides the next iteration value for the matrix serial strain.

$$
\left[\varepsilon_{s}^{m}\right]_{q+1}^{t+\Delta t}=\left[\varepsilon_{s}^{m}\right]_{q}^{t+\Delta t}-J_{q}^{-1}\left[\Delta \sigma_{s}\right]_{q}
$$

In order to have quadratic convergence, the Jacobian described in (11) has to be calculated using the constitutive tangent tensors of the components. For the calculation of these tensors, the numerical derivation technique described in [38] is used.

The composite constitutive tensor needs to be estimated when the inner loop converges. This tensor is required to calculate the global stiffness matrix in the iteration $i$ in the outer loop. To obtain the composite constitutive tensor from the fibre and matrix constitutive tensors in their parallel and serial components the following relations were used [31]:

$$
\begin{gathered}
\left(C_{p p}\right)_{c}=\left(k^{f}\left(C_{p p}\right)_{f}+k^{m}\left(C_{p p}\right)_{m}\right)+k^{f} k^{m}\left(\left(C_{p s}\right)_{f}-\left(C_{p s}\right)_{m}\right)\left(k^{m}\left(C_{s s}\right)_{f}+k^{f}\left(C_{s s}\right)_{m}\right)^{-1}\left(\left(C_{s p}\right)_{m}-\left(C_{s p}\right)_{f}\right) \\
\left(C_{p s}\right)_{c}=\left(k^{f}\left(C_{p s}\right)_{f}\left(k^{m}\left(C_{s s}\right)_{f}+k^{f}\left(C_{s s}\right)_{m}\right)^{-1}\left(C_{s s}\right)_{m}+k^{m}\left(C_{p s}\right)_{m}\left(k^{m}\left(C_{s s}\right)_{f}+k^{f}\left(C_{s s}\right)_{m}\right)^{-1}\left(C_{s s}\right)_{f}\right) \\
\left(C_{s p}\right)_{c}=\left(k^{m}\left(C_{s s}\right)_{f}\left(k^{m}\left(C_{s s}\right)_{f}+k^{f}\left(C_{s s}\right)_{m}\right)^{-1}\left(C_{s p}\right)_{m}+k^{f}\left(C_{s s}\right)_{m}\left(k^{m}\left(C_{s s}\right)_{f}+k^{f}\left(C_{s s}\right)_{m}\right)^{-1}\left(C_{s p}\right)_{f}\right) \\
\left(C_{s s}\right)_{c}=\frac{1}{2}\left(\left(C_{s s}\right)_{f}\left(k^{m}\left(C_{s s}\right)_{f}+k^{f}\left(C_{s s}\right)_{m}\right)^{-1}\left(C_{s s}\right)_{m}+\left(C_{s s}\right)_{m}\left(k^{m}\left(C_{s s}\right)_{f}+k^{f}\left(C_{s s}\right)_{m}\right)^{-1}\left(C_{s s}\right)_{f}\right)
\end{gathered}
$$

\subsection{Damage Model}

The material degradation process can be described using the Continuum Damage Mechanics model formulated by Kachanov [42]. In this work, microbuckling was modelled by a reduction of the stiffness and strength properties through a scalar damage 
variable that establishes the degradation level in each Gauss point. To simulate the constitutive law of the fibre, the isotropic damage model defined by Oller [43] was applied. This model defines different thresholds for tensile and compression stresses. The degraded stress $\sigma$ is obtained isotropically from the effective stress $\sigma_{o}$ through:

$$
\sigma=(1-d) \sigma_{o}=(1-d) C_{o} \varepsilon
$$

where $d$ is the scalar damage variable that is 0 when the material is intact and is 1 if the material is completely damaged. The effective stress $\sigma_{o}$ is calculated using the constitutive elastic law $C_{o}$ and the corresponding strain level $\varepsilon$. The degradation initiation and evolution process is described through a yielding function. Typically, this function adopts the form:

$$
F\left(\sigma_{o}, d\right)=f\left(\sigma_{o}\right)-c(d)
$$

where $c(d)$ defines the damage threshold and $f\left(\sigma_{o}\right)$ characterizes the yield surface. Damage starts to grow when $f\left(\sigma_{o}\right)$ reaches $c(d)$ and, hence, $F\left(\sigma_{o}, d\right)$ goes to zero. $F\left(\sigma_{o}, d\right)$ keeps its null value as long as damage evolves. Before any damage level is reached, the value of $c(d)$ is associated with $c^{\max }$ known as first damage threshold and is updated according to:

$$
c(d)=\max \left\{c^{\max }, \max \left\{f\left(\sigma_{o}\right)\right\}_{s}\right\} ; \quad 0 \leq s \leq t
$$

Particularly, instead of (15) the damage criteria is transformed into an equivalent form by using a monotonous increasing, semi-positive, invertible and scalar $G$ function:

$$
\bar{F}\left(\sigma_{o}, d\right)=G\left[f\left(\sigma_{o}\right)\right]-G[c(d)]
$$

In this work, the Simo-Ju generalized criteria [44] is used as yield function $f\left(\sigma_{o}\right)$. This function can be written:

$$
f\left(\sigma_{o}\right)=\varphi(r) \sqrt{\varepsilon C_{o} \varepsilon}
$$


In (18), $\varphi(r)$ is a weight function that describes the relations between the compression and tensile loads:

$$
\varphi(r)=r N+(1-r)
$$

with $N=\frac{\sigma_{c o m p}^{\max }}{\sigma_{\text {trac }}^{\max }}$, the relation between the maximum compression and tensile loads and $r$ is taken from [45] and defines the relations between the compression and tensile eigenvalues of the stress tensor:

$$
r=\frac{\sum_{i=1}^{3}\left\langle\sigma_{i}\right\rangle}{\sum_{i=1}^{3}\left|\sigma_{i}\right|}
$$

where $\langle x\rangle$ is the McAully function defined as $\langle x\rangle=\frac{1}{2}[x+|x|]$. The weight function $\varphi(r)$ transforms the tensile loads into equivalent compressive loads being weighted by the tensile strength. With this approach, the damage threshold $c(d)$ and $c^{\text {max }}$ defined in (15) and (16) must be defined using the compression stress, while the difference between the compression and the tensile threshold is defined by the parameter $\mathrm{N}$, which is a property of the material.

The evolution of the damage scalar variable $d$ in softening behaviour can be deduced from the Kuhn-Tucker conditions. From the consistency condition $\dot{\bar{F}}\left(\sigma_{o}, d\right)=0$, it can be demonstrated that [39]:

$$
d=G\left[f\left(\sigma_{o}\right)\right]
$$

The function that is proposed for $G\left[f\left(\sigma_{o}\right)\right]$ takes the form:

$$
d=G\left(f\left(\sigma_{o}\right)\right)=1-\frac{c^{\max }}{f\left(\sigma_{o}\right)} e^{A\left(1-\frac{f\left(\sigma_{o}\right)}{c^{\max }}\right)}
$$

Equation (22), formulated by Oliver et al. [45], proposes an exponential softening for the damage variable $d$. The parameter $c^{\max }$ corresponds to the maximum compressive load in a compressive pure state. The parameter $A$ shown in (22) is obtained from the 
dissipation material equation by considering a uniaxial monotonous increasing load process. The expression of the parameter $A$ in these conditions according to Oller [46], is:

$$
A=\frac{1}{\frac{g_{f}}{c^{m a x}} N^{2}-\frac{1}{2}}
$$

where $g_{f}$ is the maximum energy (per unit volume) dissipated by the material under compressive loads. The connection between the described damage model and the Fracture Mechanics model is established by matching the dissipated energy and the required energy to open new surfaces:

$$
g_{f} V=g_{f} A_{c} l=K A_{c} \rightarrow g_{f}=\frac{K}{l}
$$

where $K$ is the energy (per unit area) release rate, $A_{c}$ is the crack area and $l$ is the damage length which is perpendicular to the affected area. In a continuum material this length $l$ tends to zero, however, if this formulation is applied to a finite element code, $l$ takes a finite value. In the model proposed, $l$ corresponds to the characteristic dimension of each finite element, which can be estimated by the cubic root of the element volume.

\subsection{Model calibration and validation}

The developed model was applied to estimate the response of a laminate plate with and without hole subjected to compressive loads. Specimens of 245 x 50 x $3 \mathrm{~mm}^{3}$ and $5 \mathrm{~mm}$ diameter centred hole were modelled.

The plate was meshed by isoparametric, hexaedrical elements with eight nodes per element. The shape functions were linear and the quadrature rule for the integration of the local stiffness matrices was defined on eight Gauss points. The laminate plate was clamped at one end and was subjected to a uniform compression load at the other end. 
The model was validated by experimental data of a carbon fibre laminate T800/924C with two stacking sequences, unidirectional and $\left[ \pm 45 / 0_{2}\right]_{3 s}[40]$. The mechanical properties were taken from the scientific literature [18, 40].

To analyse the sensitivity of the results to the mesh size, four different meshes with 9600, 19968, 28800 and 44928 elements (Fig. 2) were used.
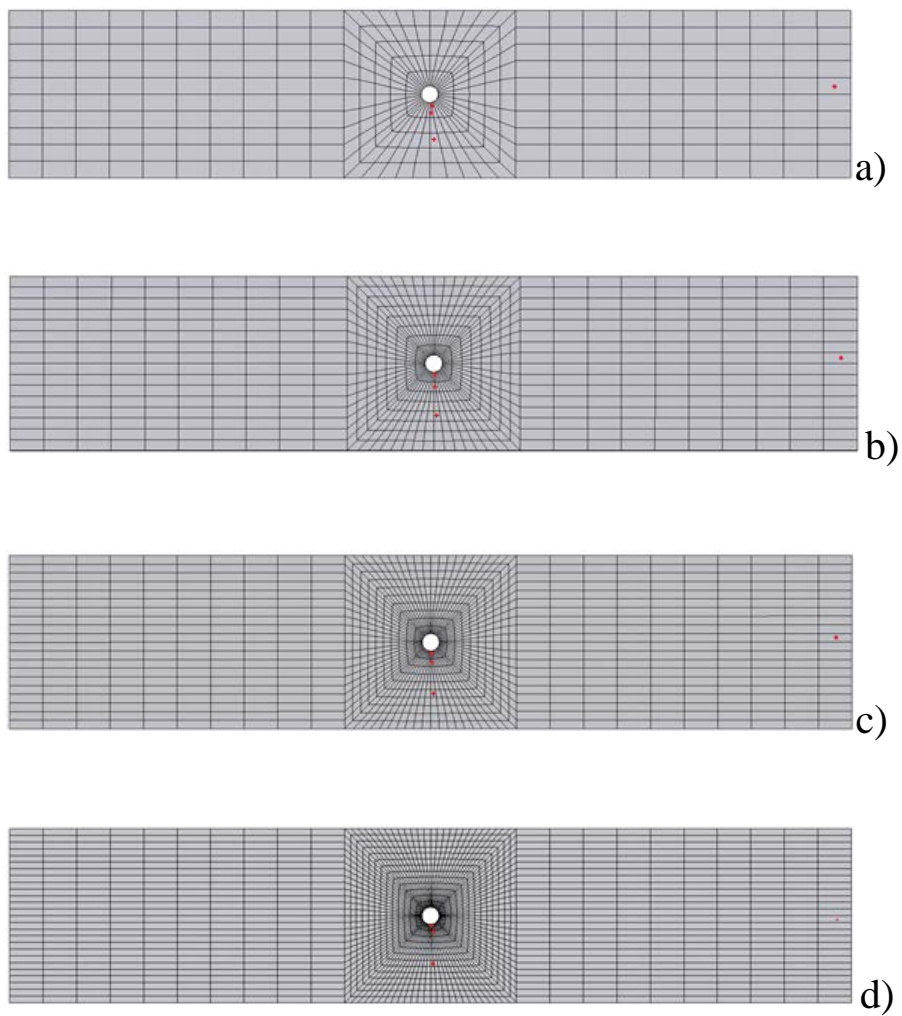

Figure 2. Meshes used in the analysis. a) 9600 elements, b) 19968 elements, c) 28800 elements, d) 44928 elements.

The global response of the laminate was not affected by the number of elements in the mesh (Fig. 3). However, near the hole, the stress field was different for each mesh. In order to estimate appropriately the stress concentration phenomenon with a moderate computational cost, a mesh with 28800 elements was selected (Fig. 4). 


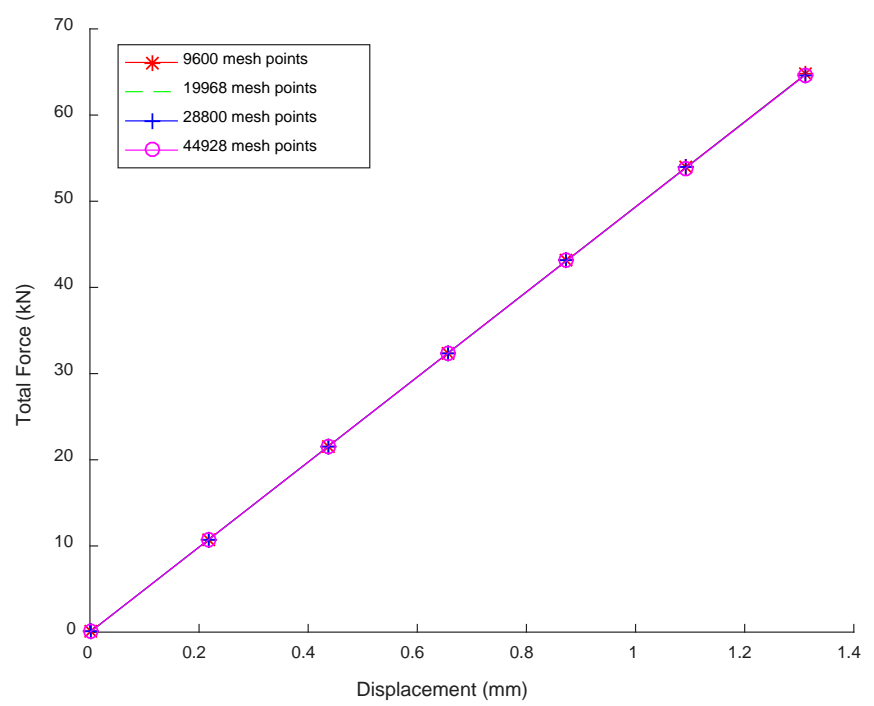

Figure 3. Applied load- displacement curve in laminate $\left[ \pm 45 / 0_{2}\right]_{3 \mathrm{~s}}$ with a $5 \mathrm{~mm}$ diameter hole

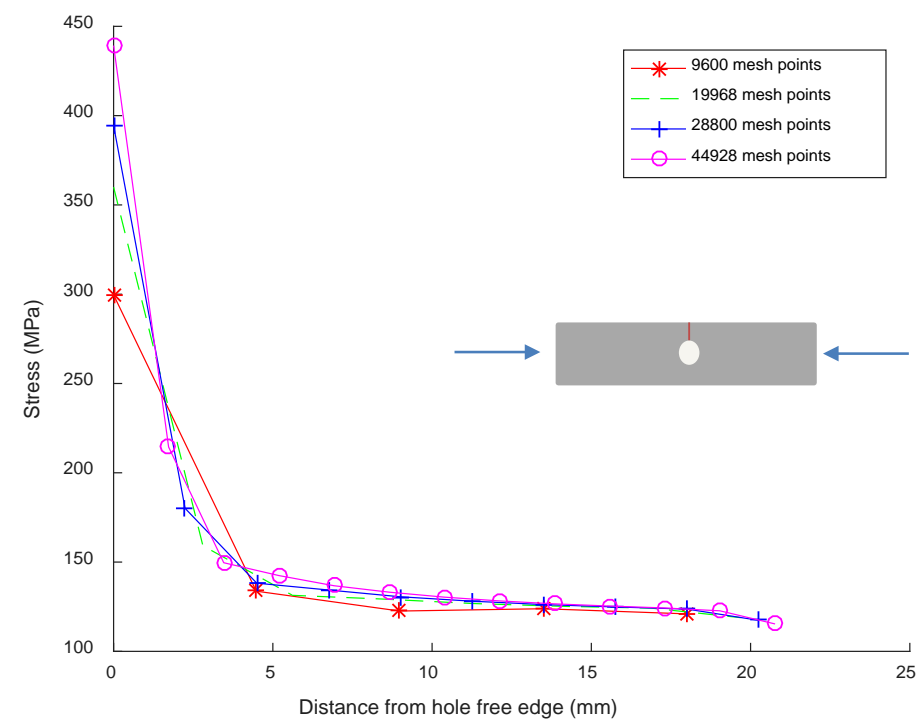

Figure 4. Stress vs. distance from hole free edge in transversal direction for different meshes in laminate $\left[ \pm 45 / 0_{2}\right]_{3 S}$ with a $5 \mathrm{~mm}$ diameter hole

The calibration was carried out using the experimental data corresponding to a unidirectional laminate subjected to uniaxial compression load [40]. In the S/PMT, the 
fibre and matrix properties are considered belonging to a different anisotropy space that can eventually become isotropic [47]. In this way, the mesoscopic behaviour of the ply is as observed in the experimental test so that equivalent properties for the constituents that allow reproduction of the experimental strain-stress curve are fixed, (Fig 5). This process provides equivalent properties for the constituents that allow the behaviour of an unnotched and notched laminate with a $\left[ \pm 45,0_{2}\right]_{3 s}$ stacking sequence to be reproduced. An excellent correlation in stiffness and damage initiation prediction, between numerical and experimental results, was found (Fig.6).

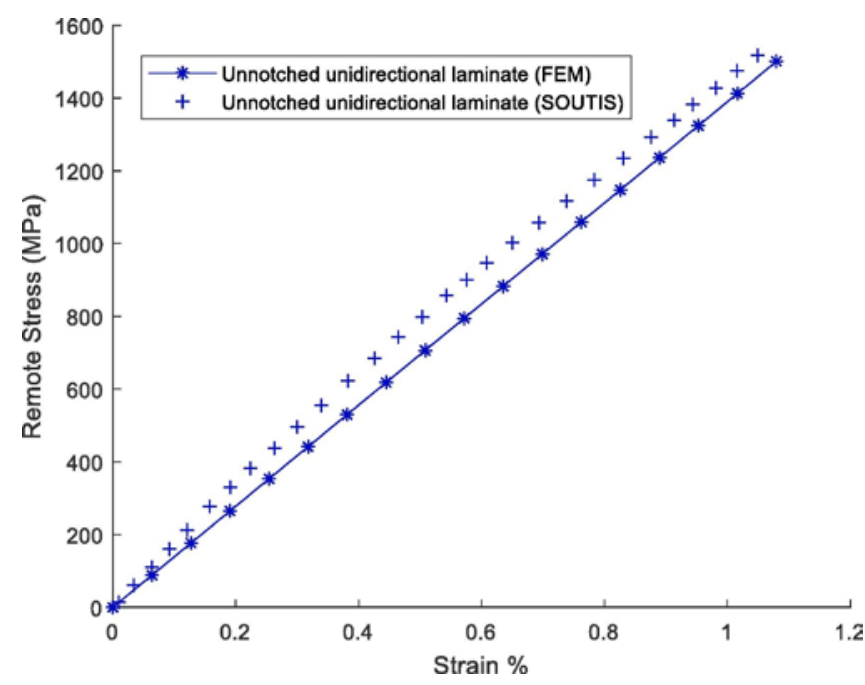

Figure 5. Compressive stress-strain curve of the T800/924C unidirectional laminate. Experimental and numerical curve after calibration.
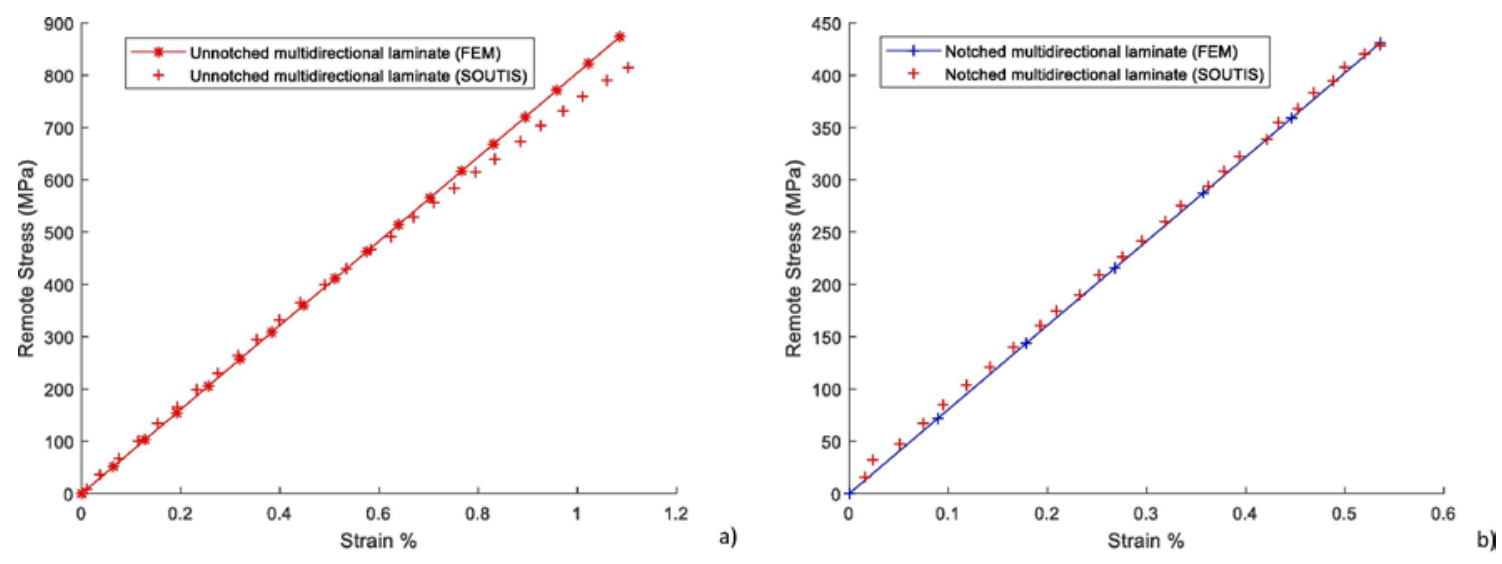
Figure 6. Comparison of experimental and numerical compressive stress-strain curves a) unnotched $[ \pm 45 / 02] 3 \mathrm{~s}$ laminate, b) laminate $[ \pm 45 / 02] 3 \mathrm{~s}$ with a $5 \mathrm{~mm}$ diameter hole.

Therefore, the proposed model can predict the damage due to fibre microbuckling in open-hole laminates subjected to compressive loads. It enables modelling the orthotropic behaviour of multidirectional laminates without the use of second or fourth order damage tensors as proposed by other authors [34, 35], which would increase the number of internal variables and the computational cost.

\section{Results}

In this section, a laminate plate with a centred hole of $5 \mathrm{~mm}$ in diameter subjected to a uniaxial compression load was studied using the proposed model. Two different laminates, $\left[45 /-45 / 0_{2}\right]_{3 s}$ and $\left[90_{2} / 0_{2}\right]_{3 s}$ of the material used in the previous section, were modelled. The interlaminar stresses that appear at the hole-edge and free-edges were analysed. In both laminates, the same strain level was applied.

The results show that the model predicts the damage localization in both laminates. The damage initiates in the middle plane of the laminate where the thickest block of plies oriented in the load direction is located. Later, the damage progressively propagates to the nearest block of layers with the same orientation, to the top and bottom of the laminate (Fig. 7). This damage can be caused by fibre microbuckling that appears in laminates subjected to compressive loads. The damage is higher in the $\left[90_{2} / 0_{2}\right]_{3 s}$ laminate than in the $\left[45 /-45 / 0_{2}\right]_{3 s}$ laminate, due to the fact that the plies at $0^{\circ}$ support more applied load than the plies at $90^{\circ}$. 

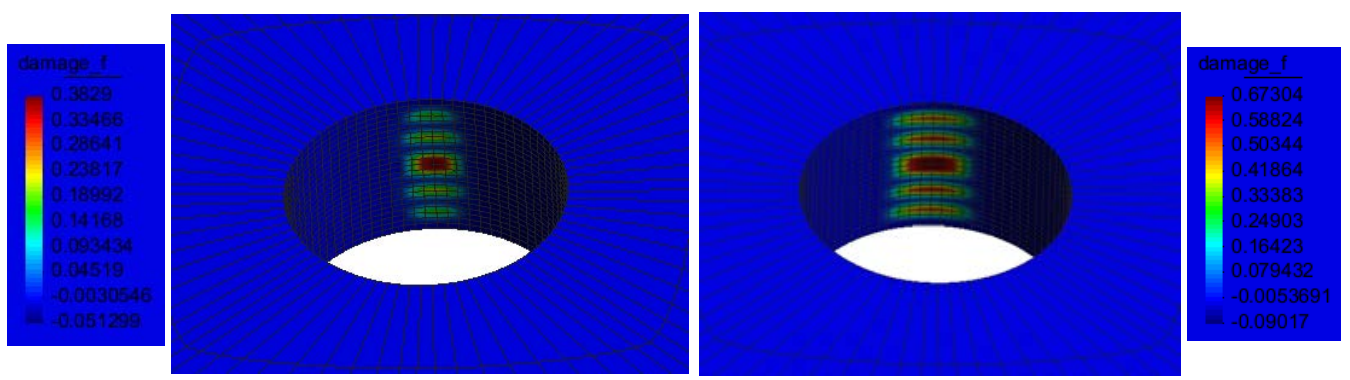

Figure 7. Localization of fibre damage initiation in $0^{\circ}$ plies. Left: Laminate $\left[45 /-45 / 0_{2}\right]_{3 s}$ Right: Laminate $\left[90_{2} / 0_{2}\right]_{3 s}$

The distributions of the interlaminar stresses around the hole are shown in Fig. 8 and Fig. 9 in the three plies of different orientation furthest to the plane of the symmetry of the laminate. The compression load is applied from the right end of the laminate plate while the fixed boundary condition is on the left end. In all the plies, the stresses in the quadrature points are represented. For this reason, the stresses in the upper ply are different from zero. Figs. 8 and 9 show that a change in the stacking sequence modifies the interlaminar stresses. In the $\left[45 /-45 / 0_{2}\right]_{3 s}$ laminate (Fig. 8), the stress $\sigma_{\mathrm{zz}}$ presents an axial symmetry around the Z-axis. In the $\left[90_{2} / 0_{2}\right]_{3 s}$ laminate, a symmetry with respect to the $\mathrm{X}$ and $\mathrm{Y}$-axes also appears (Fig. 9). 


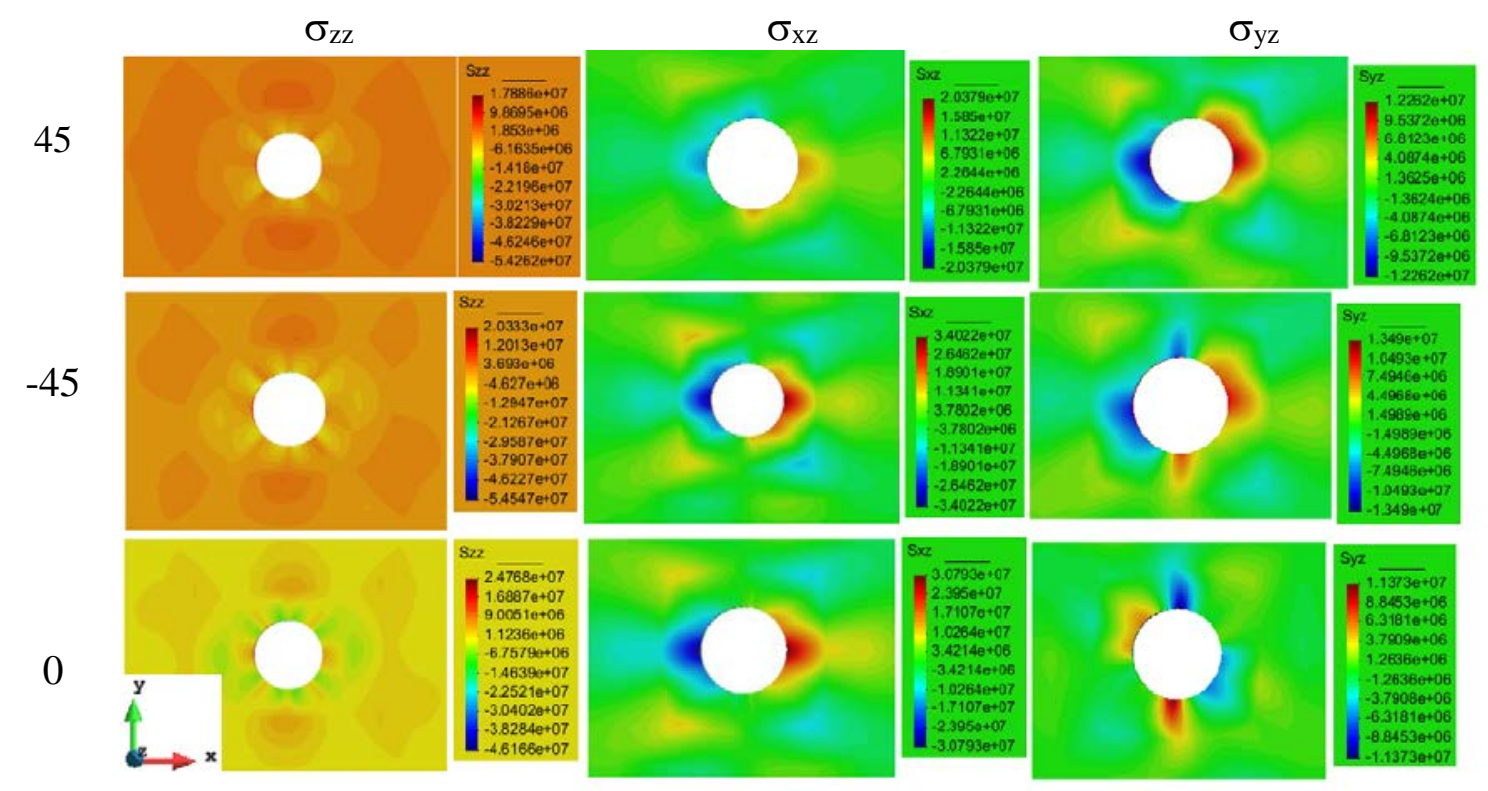

Figure 8. Stresses $\sigma_{z z}, \sigma_{x z}$ y $\sigma_{y z}$ (from left to right) for the plies with $45^{\circ},-45^{\circ}$ and $0^{\circ}$ orientations further to the plane of symmetry (from top to bottom). Laminate $\left[45 /-45 / 0_{2}\right]_{3 s}$

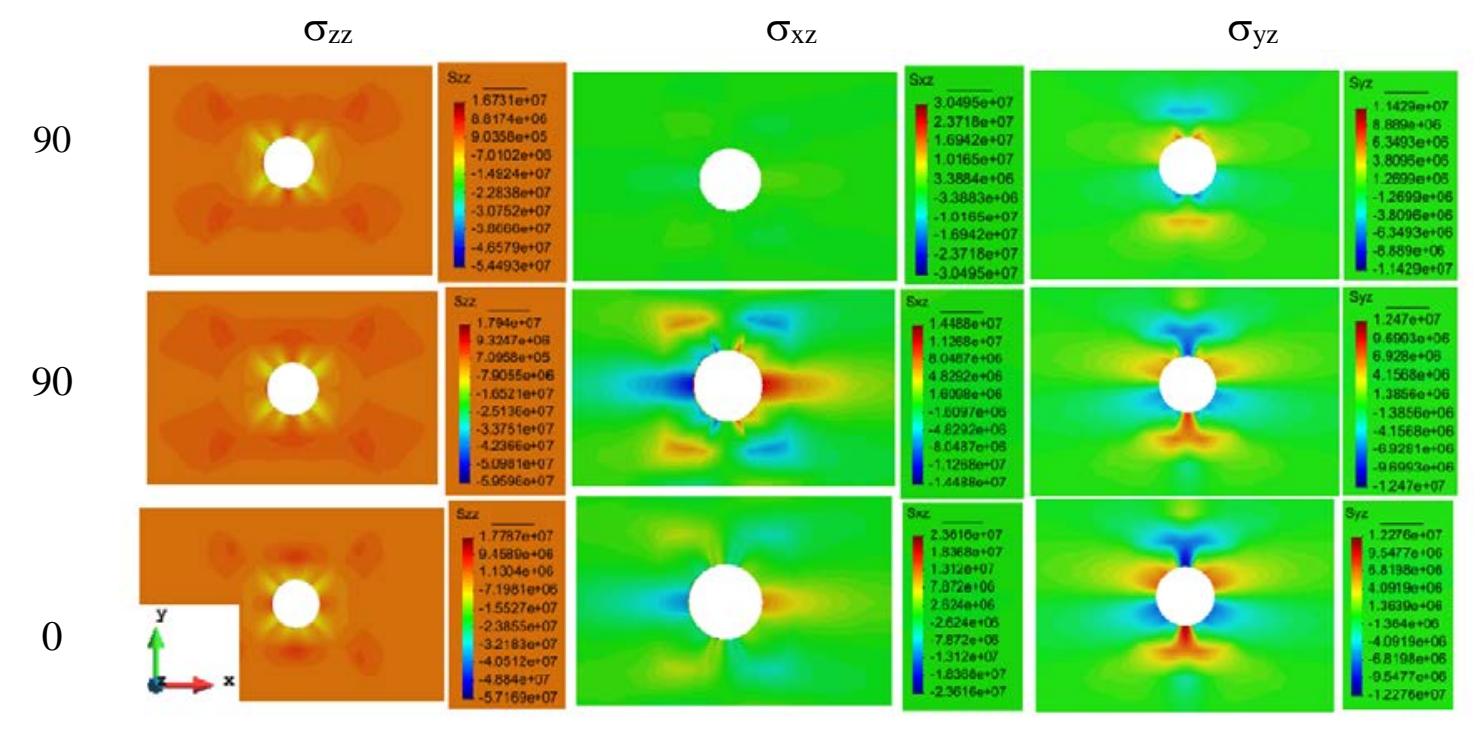

Figure 9. Stresses $\sigma_{z z}, \sigma_{x z} y \sigma_{y z}$ (from left to right) for the plies with $90^{\circ}$ and $0^{\circ}$ orientations further to the plane of symmetry (from top to bottom). Laminate $\left[90_{2} / 0_{2}\right]_{3 s}$ 
Soutis et al. [40] experimentally observed the appearance of warping in the laminate around the hole. In this work, the model reproduced that phenomenon. In both laminates, the stress $\sigma_{\mathrm{zz}}$ at the edge of the hole change from tensile to compression when the angular coordinate varies. Delamination could appear in areas with tensile stress $\sigma_{\mathrm{zz}}$, although this failure mode was not explicitly modelled.

The stress $\sigma_{x z}$ presents axial antisymmetry with respect to the Z-axis in both laminates. In the $\left[45 /-45 / 0_{2}\right]_{3 s}$ laminate, there is also symmetry with respect to the $\mathrm{X}$-axis and antisymmetry with respect to the Y-axis in the ply at $0^{\circ}$ nearest to the top surface. In the $\left[90_{2} / 0_{2}\right]_{3 s}$ laminate, this behaviour also appears in the second ply at $90^{\circ}$ of the sublaminate. The maximum shear stress $\sigma_{\mathrm{xz}}$ is twice as the stress $\sigma_{\mathrm{yz}}$ for all plies of both laminates.

In both laminates, the stress $\sigma_{\text {yz }}$ presents axial antisymmetry with respect to the Z-axis. In the $\left[90_{2} / 0_{2}\right]_{3 s}$ laminate, all the plies present symmetry with respect to the Y-axis and antisymmetry with respect to the X-axis. This behaviour is the opposite to that observed for stress $\sigma_{\mathrm{xz}}$.

The areas of the different plies, in which the highest interlaminar shear stresses appear, are the most susceptible to transverse shear failure. The maximum $\sigma_{\mathrm{xz}}$ is located at the hole-edge in the applied load direction for the two laminates analysed, and for the stress $\sigma_{\mathrm{yz}}$, the maximum value point is placed at $90^{\circ}$ from the load direction. The points at which these stresses are null are located at $90^{\circ}$ from those corresponding to the maximum values.

The evolution of the interlaminar stresses along the thickness in four locations was also analysed for the two laminates. Three of the locations correspond to elements located in 
the edge of the hole (locations A1, A2 and B) and the other to the free-edge (location C), Fig 10. The locations A1, A2 and C are on the mid-line perpendicular to the load direction. The distance between location A1 and A2 is $2 \mathrm{~mm}$ and they are in the area of highest stress $\sigma_{\mathrm{xx}}$. Location B corresponds to elements at the edge of the hole in the direction of application of the load, in which the interlaminar stress $\sigma_{\mathrm{xz}}$ is maximum. In both laminates, the stress $\sigma_{\mathrm{zz}}$ presents a symmetry with respect to the middle plane of the laminate (Fig.11). By contrast, the stresses $\sigma_{\mathrm{xz}}$ and $\sigma_{\mathrm{yz}}$ present an antisymmetric distribution with respect to the same plane (Fig.12 and 13). Fig. 11 and 12 show a high level of stress concentration in the interlaminar stress components at the hole-edge (locations A1, A2 and B) with respect to the free-edge of the laminate (location C).

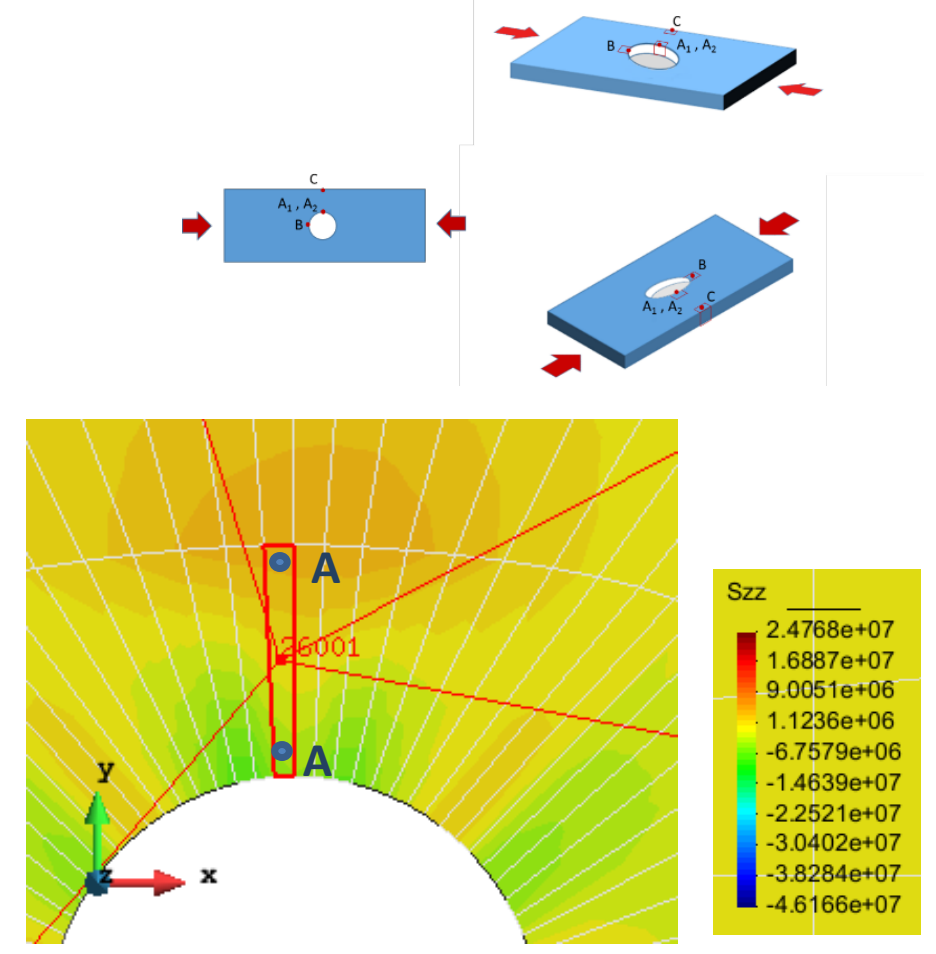

Figure 10. Location of the elements where the interlaminar stress components along the thickness are estimated close to the hole edge perpendicular to the load direction 
(Position A1 and A2) and in the load direction (position B), and at the free edge (Position C)
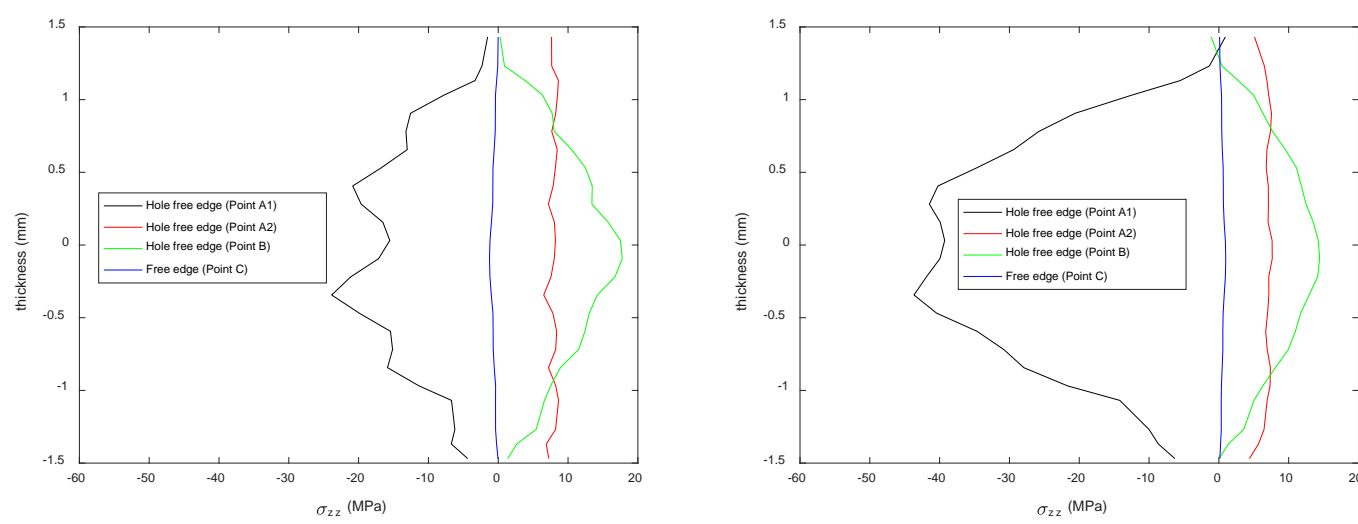

Figure 11. Stress $\sigma_{z z}$ distribution along laminate thickness. Left: Laminate $\left[45 /-45 / 0_{2}\right]_{3 s}$. Right: Laminate $\left[90_{2} / 0_{2}\right]_{3 s}$
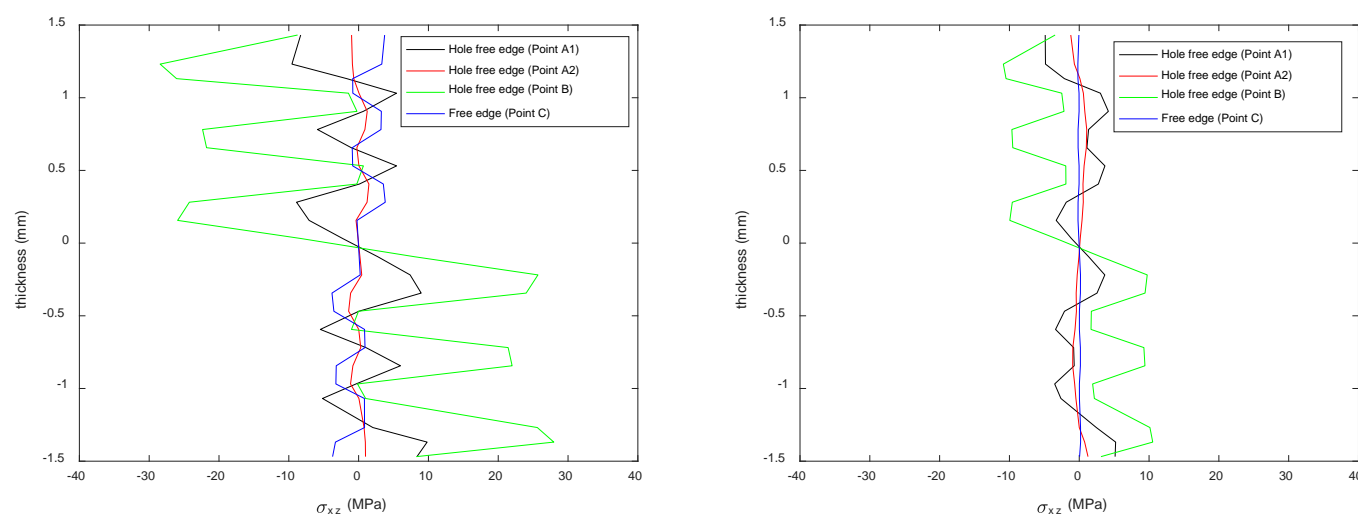

Figure 12. Stress $\sigma_{\mathrm{xz}}$ distribution along laminate thickness. Left: Laminate $\left[45 /-45 / 0_{2}\right]_{3 s}$. Right: Laminate $\left[90_{2} / 0_{2}\right]_{3 s .}$. 

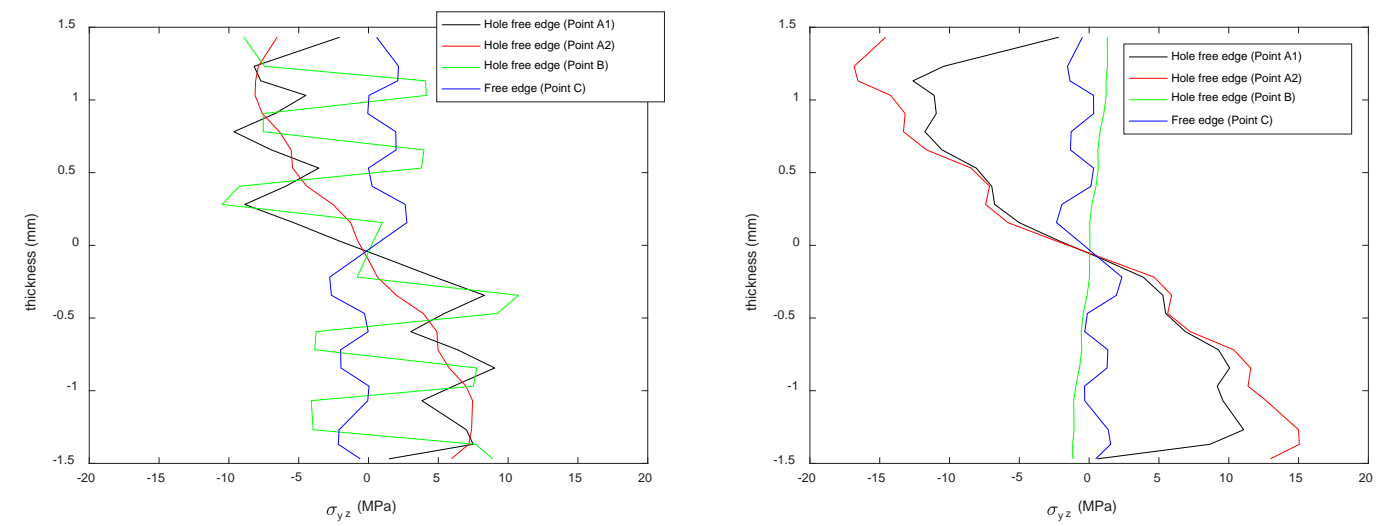

Figure 13. Stress $\sigma_{\mathrm{yz}}$ distribution along laminate thickness. Left: Laminate $\left[45 /-45 / 0_{2}\right]_{3 \mathrm{~s}}$. Right: Laminate $\left[90_{2} / 0_{2}\right]_{3 s}$.

Tensile stress $\sigma_{\mathrm{zz}}$ is observed in the locations A2 and B (at the hole-edge). For this reason, in these two areas, delamination damage can be produced. By contrast, in location $\mathrm{A} 1, \sigma_{\mathrm{zz}}$ is in compression and thus delamination is restricted. In both laminates, the distribution of tensile stress in locations A2 and B is of the same order, with the compression stress (location A1) being higher in laminate $\left[90_{2} / 0_{2}\right]_{3 s}$. The maximum stress $\sigma_{\mathrm{zz}}$ appears close to the plane of symmetry of the laminate where the largest block of plies at $0^{\circ}$ (four plies) in both laminates is located. In laminate $\left[45 /-45 / 0_{2}\right]_{3 s}$, small oscillations of this stress component appear in the ply interfaces; this phenomenon is not observed in the other laminate.

Also, in the $\left[45 /-45 / 0_{2}\right]_{3 s}$ laminate, the distribution of the interlaminar shear stresses through the thickness presents oscillations in the interface between the plies. In the other laminate, these oscillations are much less ostensible. The shear stresses $\sigma_{\mathrm{xz}}$ and $\sigma_{\mathrm{yz}}$ show sign changes along the thickness in the ply interfaces in the $\left[45 /-45 / 0_{2}\right]_{3 \mathrm{~s}}$ 
laminate. This phenomenon can encourage transverse shear failure due to the shear displacement between plies. These changes of sign do not appear in the other laminate. The stress $\sigma_{\mathrm{xz}}$ in location $\mathrm{B}$ is greater than the stress $\sigma_{\mathrm{yz}}$ in both laminates, with the highest value being found in the first of the laminates. By contrast, in location A1, the relative value of both shear stress components are the opposite, and in location A2 the two stress components are of the same order.

\section{Conclusions}

The phenomenological model proposed in this work allows to obtain the interlaminar stresses at the hole-edge and free-edge of an open-hole laminate subjected to in-plane compressive loads. The S/PMT with an isotropic continuous damage model predicted damage initiation in compression, modelling the orthotropic behaviour of the laminate. In the laminates analysed, the damage initiated in the middle plane of the laminate, where the thickest block of plies oriented in the direction of the load is located. Subsequently, the damage progressively propagated to the closest block of plies with the same orientation to the top and bottom surface. This zone can be identified, therefore, with the area affected by microbuckling, characteristic of the compression loads that are applied. These results show that is possible to characterize the damage by microbuckling with the proposed model, without using additional elements such as cohesive elements or mesh separation techniques, and thus reducing the computational cost.

The model also can predict the influence of the stacking sequence on the interlaminar stresses that appear close to the hole. The distribution of the interlaminar stresses around the hole presented symmetry with respect to the load direction and the 
perpendicular axis. Values of interlaminar stresses with different signs were found as the angular coordinate varied from $0^{\circ}$ to $360^{\circ}$. The maximum and minimum values were located in different angular positions for each stress component and laminate. The positions can be aligned with the axis of application of the load, the perpendicular axis or in points of angular coordinates at odd multiples of $45^{\circ}$.

The alternate tensile and compressive values of the stress $\sigma_{\mathrm{zz}}$ around the hole reproduced the warping observed experimentally by other authors. In this area, delamination damage could appear.

\section{Acknowledgement}

The authors thank the funds received for the development of this work from Ministry of Economy and Finance of Spain within the framework of the project DPI2013-42240-R 


\section{References}

[1] Hu FZ, Soutis C, Edge EC. Interlaminar stresses in composite laminates with a circular hole. Compos Struct 1997; 37: 223-232.

[2] Sun CT, Chu GD. Reducing free edge effect on laminate strength by edge modification. J Compos Mater 1991; 25(2): 142-61.

[3] Sihn S, Kim RY, Kawabe K, Tsai SW. Experimental studies of thin-ply laminated composites. Compos Sci Technol 2007; 67(6): 996-1008.

[4] Pipes RB. Moiré analysis of the interlaminar shear edge effect in laminated composites. J Compos Mater 1971; 5: 253-69.

[5] Islam MS, Prabhakar P. Modeling framework for free edge effects in laminates under thermomechanical loading. Composites Part B 2017; 116: 89-98.

[6] Dhanesh N, Kapuria S, Achary GGS. Accurate prediction of three-dimensional free edge stress field in composite laminates using mixed-field multiterm extended Kantorovich method. Acta Mech 2017; 228: 2895-919.

[7] Hajikazemi M, Van Paepegem W. A variational model for free-edge interlaminar stress analysis in general symmetric and thin-ply composite laminates. Compos Struct 2018; 184: 443-51.

[8] Solis A, Sánchez-Sáez S, Barbero E. Influence of ply orientation on free-edge effects in laminates subjected to in-plane loads. Compos Part B - Eng 2018; 153: 149158.

[9] Suemasu H, Naito Y, Gozu K, Aoki Y. Damage initiation and growth in composite laminates during open hole compression tests. Advanced Composite Materials. 2012; 21(3): 209-220 
[10] Suemasu H, Takahashi H, Ishikawa T. On failure mechanisms of composite laminates with an open hole subjected to compressive load. Composites Science and Technology. 2006; 66: 634-641.

[11] Ko, CC, Lin, CC. Method for calculating the interlaminar stresses in symmetric laminates containing a circular hole. AIAA Journal. 1992; 30(1): 197-204.

[12] Iarve EV, Pagano NJ. Singular full-field stresses in composite laminates with an open hole. International Journal of Solids and Structures. 2001; 38: 1-28.

[13] Hahn HT, Willianms, JG .Compression failure mechanisms in unidirectional composites. 1984. NASA Technical Memorandum 85834.

[14] Rosen BW. The tensile failure of fibrous composites. AIAA Journal 1964; 2(11): $1885-1911$.

[15] Barbero EJ. Prediction of compression strength of unidirectional polymer matrix composites. J Compos Mater 1998; 5(32): 483-502.

[16] Su ZC, Tay TE, Ridha M, Chen BY. Progressive damage modeling of open-hole composite laminates under compression. Compos Struct 2015; 122: 507-517.

[17] Wisnom MR, Hallet SR, Soutis C. Scaling effects in notched composites. Journal of Composite Materials. 2010; 44(2): 195-209.

[18] Soutis C, Curtis PT, Fleck NA. Static compression failure of notched carbon fibre composite. Proceedings: Mathematical and physical sciences 1993; 440(1901):241-256. [19] Waas AM, Babcock CD, Query J, Knauss WG. An experimental study of compression failure of fibrous laminated composites in the presence of stress concentration. International Journal Solids and Structures. 1990; 26 (9/10): 1071-98. 
[20] Moure MM, García-Castillo SK, Sanchez-Saez S, Barbero E, Barbero EJ. Influence of ply cluster thickness and location on matrix cracking evolution in openhole composite laminates. Compos Part B - Eng 2016; 95: 40-47.

[21] Green BG, Wisnom MR, Hallett SR. An experimental investigation into the tensile strength scaling of notched composites. Compos Part A - Appl S 2007; 38: 867-78. [22] Hallett SR, Green BG, Jiang WG, Wisnom MR. An experimental and numerical investigation into the damage mechanisms in notched composites. Compos Part A Appl S 2009;40: 613-24.

[23] Chen BY, Tay TE, Baiz PM, Pinho ST. Numerical analysis of size effects on openhole tensile composite laminates. Compos Part A - Appl S 2013; 47: 52-62.

[24] Leopold C, Schütt M, Liebig WV, Philipkowski T, Kürten J, Schulte K, Fiedler B. Compression fracture of CFRP laminates containing stress intensifications. Materials 2017; 10: 1039.

[25] Whitney J, Nuismer R. Stress fracture criteria for laminated composites containing stress-concentrations. J Compos Mater 1974; 8:253-65.

[26] Chen P, Shen Z, Wang JY. Prediction of the strength of notched fiber-dominated composite laminates. Compos Sci Technol 2001; 61(9): 1311-1321.

[27] Camanho PP, Erçin GH, Catalanotti G, Mahdi S, Linde P. A finite fracture mechanics model for the prediction of the open-hole strength of composite laminates. Compos Part A - Appl S 2012; 43(8): 1219-1225.

[28] Dugdale D. Yielding of steel sheets containing slits. J Mech Phys Solids 1960; 8(2): 100-104. 
[29] Barbero EJ, Cortes DH. A mechanistic model for transverse damage initiation, evolution, and stifness reduction in laminated composites. Compos Part B - Eng 2010; 41: 124-132.

[30] Moure MM, Otero F, Garcia-Castillo SK, Sanchez-Saez S, Barbero E, Barbero EJ. Damage evolution in open-hole laminated composite plates subjected to in-plane loads. Compos Struct 2015; 133: 1048-1057.

[31] Chaboche J-L. A continuum damage theory with anisotropic and unilateral damage. Rech Aeros 1995; 2: 139-147.

[32] Kachanov L. Introduction to continuum damage mechanics. Springer Netherlands, 1986.

[33] Barbero EJ, De Vivo L. A constitutive model for elastic damage in fiber-reinforced PMC laminae. Int J Damage Mech 2001; 10: 73-93.

[34] Maimí P, Camanho PP, Mayugo JA, Dávila CG. A continuum damage model for composite laminates: Part I - Constitutive model. Mech Mater 2007; 39: 897-908. [35] Wang L, Zheng C, Luo H, Wei S, Wei Z. Continuum damage modeling and progressive failure analysis of carbon fiber/epoxy composite pressure vessel. Compos Struct 2015; 134: 475-482.

[36] Rastellini F, Oller S, Salomon O, Oñate E. Composite materials non-linear modelling for long fibre reinforced laminates: Continuum basis, computational aspects and validations. Comput Struct 2008; 86 (9): 879-896.

[37] Salomon O, Rastellini F, Oller S, Oñate E. Fatigue prediction for composite materials and structures. In: Symposium on the evaluation, control and prevention of high cycle fatigue. Granada, Spain, 2005. 
[38] Martinez X, Oller S, Barbero E. Caracterización de la delaminación en materiales compuestos mediante la teoría de mezclas serie/paralelo. Revista Internacional de Métodos Numéricos para Cálculo y Diseño en Ingeniería 2010; 3(27): 192-193. [39] Martinez X, Oller S. Numerical simulation of matrix reinforced composite materials subjected to compression loads. Arch Comput Method E 2009; 16(4): 357397.

[40] Soutis C, Fleck NA, Curtis PT. Hole-hole interaction in carbon fibre/epoxy laminates under uniaxial compression. Composites 1991; 22(1): 31-38.

[41] Rastellini F. Modelización Numérica de la No-Linealidad Constitutiva de Laminados Compuestos. PhD thesis (In spanish). Polytechnic University of Catalonia (UPC). Barcelona, 2006.

[42] Kachanov L. Introduction to continuum damage mechanics. Springer Netherlands, 1986.

[43] Oller S. Fractura mecánica. Un enfoque global. Publicaciones CIMNE, 2001. [44] Simo JC, Ju JW. Strain and stress-based continuum damage models-I. Formulation. Int J Solids Struct 1987; 23(7): 821-840.

[45] Oliver J, Cervera M, Oller S, Lubliner J. Isotropic damage models and smeared crack analysis of concrete. In: Second International Conference on Computer Aided Analysis and Design of Concrete Structures. Austria, 1990.

[46] Oller S. Dinámica No Lineal. Publicaciones CIMNE, 2001.

[47] Oller S. Simulación Numérica del Comportamiento Mecánico de los Materiales Compuestos. Publicaciones CIMNE, 2003. 